\title{
Gastric and urinary bladder pressures correlate with intra-abdominal pressure in patients with morbid obesity
}

\author{
Shadi Hamoud ${ }^{1,2} \cdot$ Siham Abdelgani ${ }^{3} \cdot$ Michal Mekel $^{2,4} \cdot$ Safa Kinaneh $^{2,5} \cdot$ Ahmad Mahajna $^{2,4}$
}

Received: 2 November 2020 / Accepted: 9 June 2021 / Published online: 17 June 2021

(c) The Author(s) 2021

\begin{abstract}
Intra-abdominal pressure (IAP) affects cardio-respiratory and hemodynamic parameters and can be measured directly or indirectly by measuring gastric or urinary bladder pressure. The aim of this study was to investigate the correlation between IAP, gastric pressure and urinary bladder pressure in patients with morbid obesity, at normal and elevated levels of IAP in two positions. As well, to examine the effects of increasing IAP and patient's position on hemodynamic and respiratory parameters. Twelve patients undergoing laparoscopic bariatric surgery were included. IAP, gastric pressure, and urinary bladder pressure were measured while patients were in the supine position and after $45^{\circ}$ anti-Trendelenburg tilt. Mean inspiratory pressure, peak inspiratory pressure, and tidal volume were recorded and assessed. In supine position; directly measured IAP was $9.1 \pm 1.8 \mathrm{mmHg}$, compared to $10 \pm 3.6$ and $8.9 \pm 2.9 \mathrm{mmHg}$ in the stomach and bladder, respectively. Increasing IAP to $15 \mathrm{mmHg}$ resulted in an increased gastric pressure of $17 \pm 3.8 \mathrm{mmHg}$, and urinary bladder pressure of $14.8 \pm 3.9 \mathrm{mmHg}$. Gastric and urinary bladder pressures strongly correlated with IAP $\left(\mathrm{R}=0.875\right.$ and 0.847 , respectively). With $45^{\circ}$ antiTrendelenburg tilt; directly measured IAP was $9.4 \pm 2.2 \mathrm{mmHg}$, and pressures of $10.8 \pm 3.8 \mathrm{mmHg}$ and $9.2 \pm 3.8 \mathrm{mmHg}$ were measured in the stomach and the bladder, respectively. Increasing IAP to $15 \mathrm{mmHg}$ resulted in elevating gastric and bladder pressures to $16.6 \pm 5.3$ and $13.3 \pm 4 \mathrm{mmHg}$, respectively. Gastric and urinary bladder pressures had good correlation with IAP ( $R=0.843$ and 0.819 , respectively). Changing patient position from supine to $45^{\circ}$ anti-Trendelenburg position resulted in decreased mean and peak inspiratory pressures, and increased tidal volume. Basal IAP is high in patients with morbid obesity. IAP shows positive correlation to gastric and urinary bladder pressures at both normal and elevated levels of IAP. Anti-Trendelenburg tilt of mechanically ventilated morbidly obese patients resulted in favorable effects on respiratory parameters.
\end{abstract}

Trial Registration: The study was retrospectively registered in the NIH registry. Registration number is pending.

Keywords Intra-abdominal pressure · Gastric pressure $\cdot$ Urinary bladder pressure $\cdot$ Laparoscopy

Shadi Hamoud and Siham Abdelgani have contributed equally to this work.

Ahmad Mahajna

a_mahajna@rambam.health.gov.il

1 Department of Internal Medicine E, Rambam Health Care Campus, Haifa, Israel

2 Ruth \& Bruce Rappaport Faculty of Medicine, TechnionIsrael Institute of Technology, Haifa, Israel

3 Department of Internal Medicine A, Rambam Health Care Campus, Haifa, Israel

4 Department of General Surgery, Rambam Health Care Campus, POB 9602, 3109601 Haifa, Israel

5 Department of Physiology, The Ruth \& Bruce Rappaport Faculty of Medicine, Technion- Israel Institute of Technology, Haifa, Israel

\author{
Abbreviations \\ ACS Abdominal compartment syndrome \\ ASA American Society of Anaesthesiologist \\ GP Gastric pressure \\ HR Heart rate \\ IAH Intra-abdominal hypertension \\ IAP Intra-abdominal pressure \\ MAP Mean arterial pressure \\ MIP Mean inspiratory pressure \\ PIP Peak inspiratory pressure \\ Vt Tidal volume \\ WSACS World Society of the Abdominal Compartment \\ Syndrome
}




\section{Background}

Increased intra-abdominal pressure is a common clinical condition that can lead to severe morbidity if continued without appropriate treatment. Abdominal compartment syndrome (ACS) is a serious complication that can cause multi-organ failure (MOF) and death. ACS is defined as a sustained IAP $>20 \mathrm{mmHg}$ (with or without an abdominal perfusion pressure $<60 \mathrm{mmHg}$ ) that is associated with new organ dysfunction or failure [1].

There has been a marked improvement in management, diagnosis and treatment of intra-abdominal hypertension (IAH) and ACS based on The consensus definitions of the World Society of the Abdominal Compartment Syndrome (WSACS) that were published in 2006 [1,2] followed by the clinical practice guidelines published in 2007 [3] and updated in 2013 [4]. In addition, many surveys were conducted to determine the current state of awareness and knowledge of medical stuffs and the use of evidence-based medicine regarding IAH and ACS [5, 6].

ACS can be primary or secondary depending on whether the etiology is related to the abdominal-pelvic cavity and requiring specific intervention of a target organ in case of primary while in secondary ACS there is no abdominal disease that requires specific surgical correction, but the high abdominal pressure is associated with an organic dysfunction that requires immediate surgical decompression. Common causes to ACS include: abdominal or pelvic trauma, intra-abdominal hemorrhage, retroperitoneal hematoma or edema. Other conditions as bowel obstruction, ascites, and necrotizing pancreatitis may lead to ACS as well [7-10].

Sustained IAP results in elevated intrathoracic pressure which compromises pulmonary function, dynamics, increases afterload, decreased venous return and cardiac output. Perfusion to the kidneys and intestinal mucosa is severly reduced [11-14]

Early diagnosis and treatment of IAH is essential to avoid MOF and death. There is still controversy regarding the ideal method for measuring IAP. A variety of studies suggest to frequently measure IAP in critically il patients. Current practice assesses IAP indirectly through the measurement of intra vesicular pressure, however, only few studies have been performed to establish the actual relationship between IAP and urinary bladder pressure (UBP) [15-17]. In obese patients no studies have validated this technique.

The aims of this study were to asses the basal IAP and to investigate the correlation between IAP, gastric pressure (GP) and urinary bladder pressure (UBP), in patients with morbid obesity (body mass index- BMI $>40 \mathrm{~kg} / \mathrm{m}^{2}$ ) who underwent bariatric surgery. The measurements were performed at normal and elevated levels of IAP in two positions: supine and 45 degrees anti-trendelenburg tilt. The effect of increasing IAP and change in the patient position on hemodynamic parameters (mean arterial pressure and heart rate) and respiratory parameters (mean inspiratory pressure, peak inspiratory pressure and tidal volume) were evaluated as well.

\section{Methods}

\subsection{Patients}

Male and female patients aged $\geq 18$ years with morbid obesity were included in the study, while undergoing bariatric surgery in the Department of General Surgery at Rambam Health Care Campus (Rambam). Main exclusion criteria were any contraindications to laparoscopic surgery or urethral catheterization; known intra-abdominal adhesions or ventral hernia due to previous surgery; chronic obstructive pulmonary disease $\left(\mathrm{PaCo}_{2}>50 \mathrm{mmHg}, \mathrm{FEV}_{1}<1 \mathrm{~L}\right)$; or marked left ventricular dysfunction (left ventricular ejection fraction $<25 \%$ ).

\subsection{Experimental protocol}

The study was approved by Rambam's ethics committee (ethics number: 0019-12), and consent was obtained from all the participants. After general anesthesia was induced, a nasogastric tube and urinary Foley catheter were inserted. The study was conducted in two stages: (1) while patients were in the supine position, IAP was measured and adjusted for $5 \mathrm{~min}$, and then (2) IAP was increased to $15 \mathrm{mmHg}$ by insufflation of $\mathrm{CO} 2$ for 5 min. Gastric and urinary bladder pressures were measured together with hemodynamic and respiratory parameters at each stage. Subsequently, the patient was up-tilted to $45^{\circ}$ anti-Trendelenburg position and pressure and hemodynamic measurements were repeated.

\subsubsection{Measurement of intra-abdominal pressure}

The pressure within the abdominal cavity was measured directly using an automatic $\mathrm{CO} 2$ insufflation measurement device (KARL STORZ Endoskope 264,320 20, Tuttlingen, Germany).

\subsubsection{Gastric pressure}

Following insertion of the nasogastric tube, the stomach was drained and filled with $50 \mathrm{ml}$ of normal saline. A rigid pressure tube was connected to the gastric tube using a male to male connector at one end, and to the monitor through a pressure transducer at the other end. The system was flushed 
with normal saline and pressure transducer zeroed at the mid axillary line.

\subsection{Urinary bladder pressure}

A Foley catheter was placed into the urinary bladder. The bladder was drained and filled with $50 \mathrm{ml}$ of sterile normal saline. The drainage tube was clamped just beyond the aspiration port, and a 16-gauge needle connected to the rigid pressure tube was inserted into the port. The tube was connected to the monitor by a pressure transducer. The system was flushed with normal saline and the pressure transducer zeroed using the symphysis pubis as the zero reference point.

\subsection{Statistical analysis}

Sample size calculation was based on the http://biomath. info/power/prt.htm for paired samples. We assumed that the mean difference between the two measurements will be 2 units with $2.5 \mathrm{SD}$. In this case we needed to recruit less than 15 patients. Variables are presented as mean and standard deviation. Statistical analysis included the $\chi^{2}$ test for categorial variables and Student t-test for continuous variables. $\mathrm{P}$-value $<0.05$ was considered statistically significant.

\section{Results}

Of 13 patients included in the study, one was subsequently excluded due to a huge ventral hernia after previous open cholecystectomy. Table 1 summarizes participants' characteristics. There were eight females and four males with an average age of $35 \pm 11$ years, and average BMI of $43 \pm 5.8 \mathrm{~kg} / \mathrm{m}^{2}$. The American Society of Anaesthesiologist (ASA) physical status score was II for eight patients and III for four patients.

\subsection{Correlation between directly measured IAP, GP and UBP}

When subjects were in the supine position; the directly measured IAP was $9.1 \pm 1.8 \mathrm{mmHg}$, compared to pressures

Table 1 Characteristics of patients

\begin{tabular}{llc}
\hline & $\mathrm{n}=12$ & Range \\
\hline Males & 4 & \\
Females & 8 & \\
Average age (years, range) & $35 \pm 12$ & $18-55$ \\
Weight (kilograms) & $120 \pm 20$ & $102-150$ \\
Height (meters) & $1.66 \pm 0.9$ & $1.54-1.80$ \\
BMI $\left(\mathrm{kg} / \mathrm{m}^{2}\right)$ & $43 \pm 5.8$ & $37-55$ \\
\hline
\end{tabular}

of $10 \pm 3.6 \mathrm{mmHg}$ and $8.9 \pm 2.9 \mathrm{mmHg}$ in the stomach and urinary bladder, respectively. Increasing IAP to $15 \mathrm{mmHg}$ resulted in an increased GP of $17 \pm 3.8 \mathrm{mmHg}$, and increased UBP to $14.8 \pm 3.9 \mathrm{mmHg}$ (Figs. 1 and 2). The correlation coefficients of GP and UBP to IAP were 0.875 and 0.847 , respectively (Table 2). After elevating patients to 45 degrees anti-Trendelenburg position, direct IAP increased to $9.4 \pm 2.2$, compared to $10.8 \pm 3.8$ and $9.2 \pm 3.8 \mathrm{mmHg}$ in the stomach and the urinary bladder, respectively. Increasing IAP to $15 \mathrm{mmHg}$ resulted in an increased GP of $16.6 \pm 5.3 \mathrm{mmHg}$, and of the UBP to $13.3 \pm 4.9 \mathrm{mmHg}$, while GP and UBP strongly correlated with IAP $(\mathrm{R}=0.843$ and 0.819 , respectively) (Table 2).

\subsection{Effect of increased IAP on mean arterial pressure (MAP) and heart rate (HR)}

In the supine position, increasing the IAP to $15 \mathrm{mmHg}$ resulted in an elevation of the MAP from $87 \pm 11 \mathrm{mmHg}$ to $104 \pm 11 \mathrm{mmHg}(\mathrm{p}<0.01)$. After $45^{\circ}$ anti-Trendelenburg tilt, a similar increase of IAP resulted in an elevated MAP from $99 \pm 20 \mathrm{mmHg}$ to $106 \pm 14 \mathrm{mmHg}(\mathrm{p}=0.33$, Table 2$)$. In the supine position, increasing IAP to $15 \mathrm{mmHg}$ caused no change in the HR $(75 \pm 13 \mathrm{bpm}$ and $75 \pm 16 \mathrm{bpm}, \mathrm{p}=0.71)$. Also after $45^{\circ}$ anti-Trendelenburg tilt, a similar increase of IAP resulted in non-significant elevation of the HR from $78 \pm 17 \mathrm{bpm}$ to $81 \pm 17 \mathrm{bpm}(\mathrm{p}=0.25$, Table 2$)$.

\subsection{Effect of increased IAP on mean inspiratory pressure (MIP), peak inspiratory pressure (PIP) and $\mathrm{Vt}$}

In the supine position, increasing IAP to $15 \mathrm{mmHg}$ resulted in MIP elevation from $11 \pm 2 \mathrm{mmHg}$ to $13 \pm 3 \mathrm{mmHg}$ ( $p<0.001)$. After elevating the patients to the $45^{\circ}$ anti-Trendelenburg position, a similar increase of the IAP resulted in MIP elevation from $10 \pm 2.4 \mathrm{mmHg}$ to $12 \pm 3 \mathrm{mmHg}$ $(\mathrm{p}<0.001$, Table 2). Similarly, in the supine position, increasing the IAP to $15 \mathrm{mmHg}$ resulted in an increase of PIP from $27 \pm 1 \mathrm{mmHg}$ to $31 \pm 2 \mathrm{mmHg}(\mathrm{p}<0.005)$. After tilting patients to $45^{\circ}$ anti-Trendelenburg position, a similar IAP increase resulted in PIP elevation from $24 \pm 3 \mathrm{mmHg}$ to $28 \pm 3 \mathrm{mmHg}(\mathrm{p}<0.001$, Table 2$)$.

In the supine position, increasing IAP to $15 \mathrm{mmHg}$ resulted in a decreased $\mathrm{Vt}$ from $0.60 \pm 0.1$ lit to $0.52 \pm 0.1$ lit $(p=0.01)$. After a tilt to $45^{\circ}$ anti-Trendelenburg position, a similar increase of the IAP decreased the $\mathrm{Vt}$ from $0.65 \pm 1$ lit to $0.62 \pm 1$ lit $(\mathrm{p}=0.13$, Table 2$)$. While patients were with IAP of $15 \mathrm{mmHg}$, changing the patient position from supine to the $45^{\circ}$ anti-Trendelenburg position resulted in decreased MIP (from $13 \pm 3$ to $12 \pm 3 \mathrm{mmHg}, \mathrm{p}=0.021$ ) and PIP (from $31.2 \pm 2.3$ to $28.1 \pm 3.3 \mathrm{mmHg}, \mathrm{p}=0.004)$, and increased $\mathrm{Vt}$ (from $0.52 \pm 0.1$ to $0.62 \pm 1$ lit, $\mathrm{p}=0.016$ ). 
Fig. 1 Correlation between directly measured Intra-abdominal Pressure $(\mathrm{mmHg})$ and Gastric Pressure (mmHg) in two positions; Supine and $45^{\circ}$ antiTrendelenburg position. Values are presented as mean $\pm \mathrm{SD}$

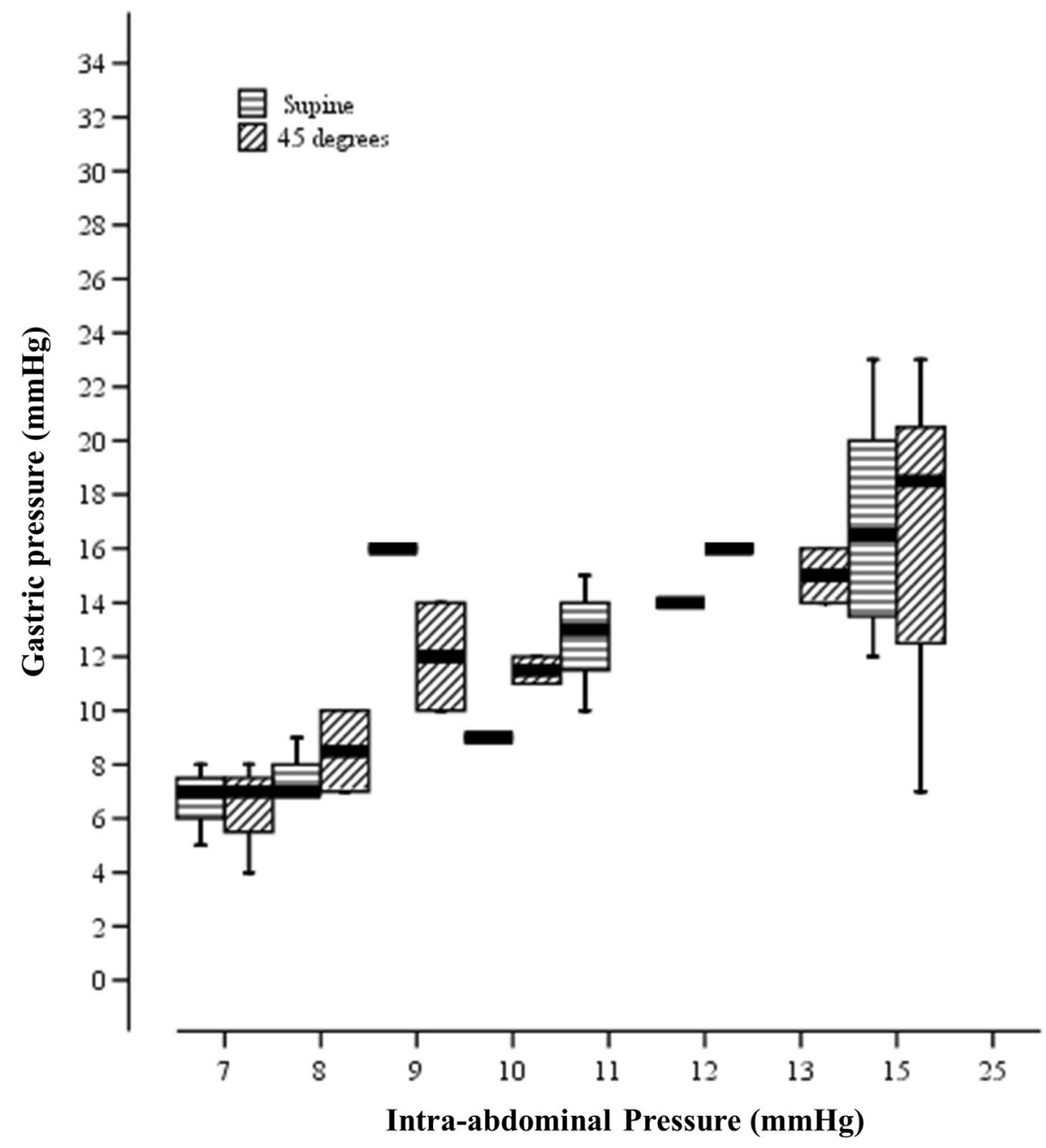

\section{Discussion}

Morbid obesity has been proclaimed by the WHO Statement as the epidemic of the 21 st Century $[18,19]$, and is associated with considerable morbidity and mortality. With the widespread success of damage control laparotomy, ACS has become a virtual epidemic in trauma centers throughout the world [20-22]. Increasing numbers of critically ill patients are obese; therefore the special consideration of IAP and ACS in this patient population has become significantly more relevant.

There is an exponential increase in studies on IAP and ACS in non-obese patients in the literature, but very few studies include the measurement of IAP in obese patients.

The diagnosis of IAH or ACS is heavily dependent on the reproducibility of the IAP measurement technique. Over time, literature has suggested many methods to assess IAP. The ideal tool is still controversial [15]. Malbrain MLNG et al. showed in there study a poor correlation between IAP and abdominal perimeter [23]. Other studies have shown that a clinical estimation of IAP examiner's feeling of the tenseness of the abdomen is not accurate, with a low sensitivity [24].

Consequently, the IAP needs to be measured with a more accurate and reliable tool. Different direct and indirect measurement methods have been reported [25, 26]. Traditionally, the urinary bladder pressure has been used as the method of choice for measuring the IAP. The technique was originally described by Kron et al. [8]. It is safe, minimally invasive, and has minimal side effects and complications.

Another useful site for measuring IAP is in the stomach through a nasogastric tube, which can be used when the patient has no Foley catheter in place, or when bladder pressure measurement is not possible due to absence of free contractibility of the bladder wall [27]. GP measurement is cheap, does not interfere with urine output, and has no risk of infection. Both methods are ideal for screening and monitoring of critically ill patients.

Several studies have addressed the validation of indirect versus direct measurements of the IAP during laparoscopy in non-obese patients. Yol et al. compared bladder pressure with direct insufflation pressure during laparoscopic 
Fig. 2 Correlation between directly measured Intra-abdominal Pressure $(\mathrm{mmHg})$ and Urinary Bladder Pressure ( $\mathrm{mmHg}$ ) in two positions; Supine and $45^{\circ}$ anti-Trendelenburg position. Values are presented as mean $\pm \mathrm{SD}$

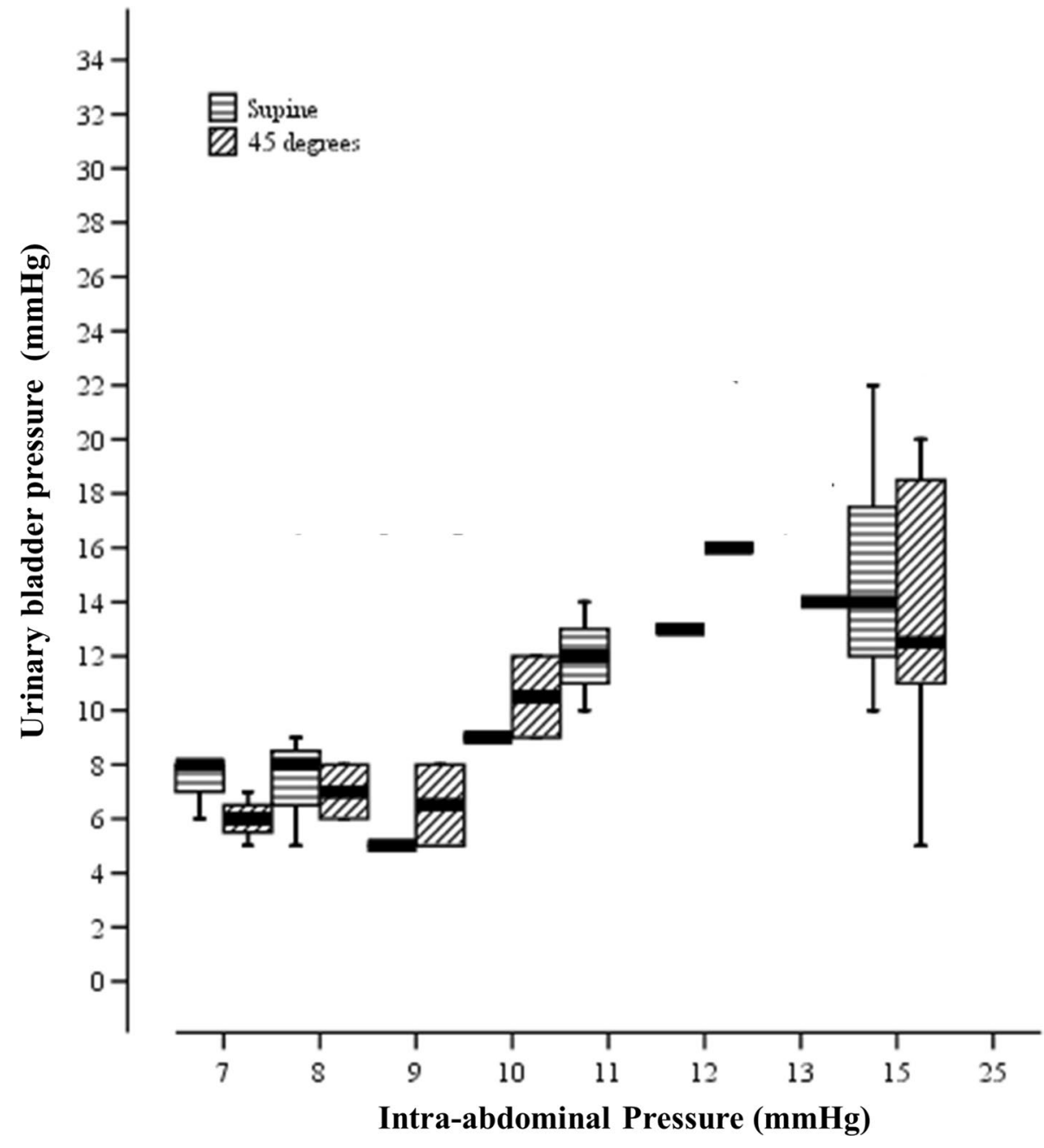

cholecystectomy in 40 patients, and obtained a positive correlation between the two measurements $(R=0.973$, $\mathrm{P}<0.0001$ ) [28]. Likewise, Fusco et al. compared direct laparoscopic insufflation pressure with bladder pressure in patients undergoing laparoscopy, and demonstrated a good correlation in pressure values across the IAP range from 0 to $25 \mathrm{mmHg}$ between the direct and indirect measurement methods [29]. There have been no studies comparing the direct IAP with urinary bladder or gastric pressures in patients with morbid obesity.

In the current study, we found that the baseline IAP measured in the urinary bladder and stomach of patients with morbid obesity was higher than values reported in nonobese subjects, consistent with the literature. Sugerman et al. showed that the urinary bladder pressure was significantly higher in obese compared to non-obese patients ( $18 \pm 0.7$ vs. $7 \pm 1.5 \mathrm{cmH}_{2} \mathrm{O}$, respectively), and concluded that increased IAP, as reflected in urinary bladder pressure, contributes to health risks associated with severe obesity [30]. Similarly, Lambert et al. concluded that IAP is elevated in patients with morbid obesity, and increased IAP is a function of central obesity associated with increased morbidity [31]. In our study, we included twice female patients than males. Although female obesity is different from male obesity (abdominal impact), our results demonstrated similar behavior of IAP when comparing male and female patients, thus one can exclude impact of gender on IAP- neither directly measured nor indirectly (GP or UBP). Moreover, our results are in accordance with the study of Smit et al. that had demonstrated a direct correlation between BMI and IAP, whereas correlation between IAP and indices of central obesity were not significant [32].

The chronic elevation of IAP can explain why many severely obese patients, especially those with sleep apnea and hypoventilation, have found they must sleep in the sitting position, presumably to lower the effects of increased IAP on their thoracic cavity. In our study, we found that changing the patients' position from supine to $45^{\circ}$ antiTrendelenburg elevated position decreased the inspiratory pressures and increased $\mathrm{Vt}$, findings that can be translated to a decrease in respiratory effort. Furthermore, increasing IAP from baseline to $15 \mathrm{mmHg}$ resulted in a rise in 
Table 2 Correlation between IAP, GP and UBP in supine and with 45 degree antitrendelenburg elevation, in baseline and with wlwvated IAP to $15 \mathrm{mmHg}$

\begin{tabular}{|c|c|c|c|c|c|c|c|c|}
\hline & \multirow{2}{*}{$\begin{array}{l}\text { Position } \\
\text { Supine }\end{array}$} & \multicolumn{4}{|c|}{$\begin{array}{l}\text { Mean (SD) by group of IAP and significance of } \\
\text { position's diff }\end{array}$} & \multirow{2}{*}{$\begin{array}{l}\text { p-value (IAP: } \\
\text { baseline Vs } \\
15 \mathrm{mmHg} \text { ) } \\
\text { NA }\end{array}$} & \multicolumn{2}{|c|}{$\begin{array}{l}\text { Correlation with } \\
\text { IAP (all groups) }\end{array}$} \\
\hline & & $9.1(1.8)$ & $\mathrm{p}$ - value $\mathrm{a}^{\mathrm{a}}$ & $15.0(0.00)$ & $\mathrm{p}-$ value $^{\mathrm{b}}$ & & $\mathrm{R}$ & $\mathrm{p}$-value \\
\hline IAP & 45 Degr & $9.4(2.2)$ & & $15.0(0.00)$ & & NA & & \\
\hline \multirow[t]{2}{*}{ GI } & Supine & $10.0(3.6)$ & & $17.00(3.8)$ & & $<0.001$ & 0.875 & $<0.001$ \\
\hline & 45 Degr & $10.8(3.8)$ & 0.713 & $16.6(5.3)$ & 0.531 & $<0.001$ & 0.843 & $<0.001$ \\
\hline \multirow[t]{2}{*}{ Bladder } & Supine & $8.9(2.9)$ & & 14.8 (3.9) & & $<0.001$ & 0.847 & $<0.001$ \\
\hline & 45 Degr & $9.2(3.8)$ & 0.686 & $13.3(4.9)$ & 0.326 & $<0.001$ & 0.819 & $<0.001$ \\
\hline \multirow[t]{2}{*}{ MAP } & Supine & $87.0(11)$ & & $104.0(11.0)$ & & $<0.01$ & 0.634 & $<0.001$ \\
\hline & 45 Degr & $99.0(20.0)$ & 0.760 & $106.0(14.0)$ & 0.695 & 0.33 & 0.291 & 0.085 \\
\hline \multirow[t]{2}{*}{ HR } & Supine & 75 (13) & & $75(16)$ & & 0.71 & 0.184 & 0.284 \\
\hline & 45 Degr & 78 (17) & 0.718 & $81(17)$ & 0.181 & 0.25 & 0.152 & 0.377 \\
\hline \multirow[t]{2}{*}{ MIP } & Supine & $11(2)$ & & $13(3)$ & & $<0.001$ & 0.407 & 0.014 \\
\hline & $45 \mathrm{Degr}$ & $10(2)$ & 0.788 & $12(3)$ & 0.021 & $<0.001$ & 0.447 & 0.006 \\
\hline \multirow[t]{2}{*}{ PIP } & Supine & $27(1)$ & & $31(2)$ & & $<0.005$ & 0.777 & $<0.001$ \\
\hline & 45 Degr & $24(3)$ & 0.792 & $28(3)$ & 0.004 & $<0.001$ & 0.748 & $<0.001$ \\
\hline \multirow[t]{2}{*}{$\mathrm{Tv}$} & Supine & $0.63(0.1)$ & & $0.52(0.1)$ & & 0.01 & -0.495 & 0.002 \\
\hline & 45 Degr & $0.65(0.1)$ & 0.770 & $0.62(0.1)$ & 0.016 & 0.130 & -0.366 & 0.028 \\
\hline
\end{tabular}

$p<0.05$ is considered statistically significant

${ }^{a}$ By comparing of correlations with IAP

${ }^{\mathrm{b}}$ By Wilcoxon Signed Ranks Test the MAP with no change in the HR, both in the supine position and after a tilt of $45^{\circ}$ anti-Trendelenburg. Various mechanisms, such as venous compression caused by elevated IAP (with compression of the abdominal vasculature and organs), and the pharmacological action of the absorbed $\mathrm{CO}_{2}$, have been proposed to explain these transient adverse hemodynamic effects [33, 34]. It has also been shown that increased IAP during carbon dioxide pneumoperitoneum is associated with increased mean arterial blood pressure and systemic vascular resistance $[35,36]$.

In accordance with Lambert et al. who demonstrated elevated IAP in patients with morbid obesity compared to non-obese patients [31], we also found that baseline IAP is high in patients with morbid obesity, and obtained a good correlation between the direct IAP measured by laparoscopic insufflation route on the one hand, and urinary bladder and gastric pressures measured in morbidly obese patients on the other hand, both at normal and elevated levels of IAP. In addition, we found that changing the patients' position from the supine position to $45^{\circ}$ anti-Trendelenburg elevation position caused decreased mean and peak inspiratory pressures, while increasing Vt. Therefore, patients with increased IAP are expected to benefit from the anti-Trendelenburg position as it improves respiratory parameters without hemodynamic compromise.

\section{Conclusions}

Our study demonstrated that in obese patients there is good correlation between directly measured IAP and indirectly measured pressures through the stomach or the urinary bladder. Changing the position of the patient with increased IAP to the anti-Trendelenburg position is helpful in improving respiratory parameters without interference to the patient's hemodynamic status. Small number of participants is a limitation in our study, though the consistent results in all the participants allows us to apply our results to the obese patioents population. Future studies with more participants would strengthen our findings.

Acknowledgements Authors thank Mrs. Ronit Leiba for her valuable assisstance in the statistical analysis.

Authors' contributions $\mathrm{AH}$ and MM designed the study and performed the intra-operative measurements. SH, SA and AH participated in manuscript writing and preparing for publication. SH, SK and $\mathrm{AH}$ performed data collection and analysis.

Funding This study had no financial support. 
Data Availability All data generated or analysed during this study are included in this published article.

\section{Declarations}

Conflict of interest The authors declares that they have no competing interests.

Ethical approval The study was approved by Rambam's ethics committee (ethics number: 0019-12), and written consent was obtained from all the participants. All authors have read and approved the manuscript.

Open Access This article is licensed under a Creative Commons Attribution 4.0 International License, which permits use, sharing, adaptation, distribution and reproduction in any medium or format, as long as you give appropriate credit to the original author(s) and the source, provide a link to the Creative Commons licence, and indicate if changes were made. The images or other third party material in this article are included in the article's Creative Commons licence, unless indicated otherwise in a credit line to the material. If material is not included in the article's Creative Commons licence and your intended use is not permitted by statutory regulation or exceeds the permitted use, you will need to obtain permission directly from the copyright holder. To view a copy of this licence, visit http://creativecommons.org/licenses/by/4.0/.

\section{References}

1. Malbrain ML, Cheatham ML, Kirkpatrick A, Sugrue M, Parr $\mathrm{M}$, De Waele J, et al. Results from the international conference of experts on intra-abdominal hypertension and abdominal compartment syndrome. I Definitions Intensive Care Med. 2006;32(11):1722-32.

2. Malbrain ML, Cheatham ML. Definitions and pathophysiological implications of intra-abdominal hypertension and abdominal compartment syndrome. Am Surg. 2011;77(Suppl 1):6-11.

3. Cheatham ML, Malbrain ML, Kirkpatrick A, Sugrue M, Parr M, De Waele J, Balogh Z, Leppaniemi A, Olvera C, Ivatury R, D'Amours S, Wendon J, Hillman K, Wilmer A. Results from the international conference of experts on intra-abdominal hypertension and abdominal compartment syndrome. II Recommendations Intensive Care Med. 2007;33:951-62.

4. Kirkpatrick AW, Roberts DJ, De Waele J, Jaeschke R, Malbrain ML, De Keulenaer B, Duchesne J, Bjorck M, Leppaniemi A, Ejike JC, et al. Intra-abdominal hypertension and the abdominal compartment syndrome: updated consensus definitions and clinical practice guidelines from the World Society of the Abdominal Compartment Syndrome. Intensive Care Med. 2013;39(7):1190_ 206. https://doi.org/10.1007/s00134-013-2906-z.

5. Wise R, Rodseth R, Blaser A, Roberts D, De Waele J, Kirkpatrick A, De Keulenaer B, Malbrain M. The Abdominal Compartment Society FTW Awareness and knowledge of intra-abdominal hypertension and abdominal compartment syndrome: results of a repeat, international, cross-sectional survey. Anaesthesiol Intensive Ther. 2019;51(3):186-99. https://doi.org/10.5114/ait.2019. 87648.

6. De Waele JJ, Cheatham ML, Malbrain ML, Kirkpatrick AW, Sugrue M, Balogh Z, Ivatury R, De Keulenaer B, Kimball EJ. Recommendations for research from the international conference of experts on intra-abdominal hypertension and abdominal compartment syndrome. Acta Clin Belg. 2009;64:203-9.

7. Saggi BH, Sugerman HJ, Ivatury RR, Bloomfield GL. Abdominal compartment syndrome. J Trauma. 1998;45(3):597-609.
8. Kron IL, Harman PK, Nolan SP. The measurement of intraabdominal pressure as a criterion for abdominal re-exploration. Ann Surg. 1984;199(1):28-30.

9. Burch JM, Moore EE, Moore FA, Franciose R. The abdominal compartment syndrome. Surg Clin North Am. 1996;76(4):833-42.

10. Fietsam R Jr, Villalba M, Glover JL, Clark K. Intra-abdominal compartment syndrome as a complication of ruptured abdominal aortic aneurysm repair. Am Surg. 1989;55(6):396-402.

11. Schein M, Wittmann DH, Aprahamian CC, Condon RE. The abdominal compartment syndrome: the physiological and clinical consequences of elevated intra-abdominal pressure. J Am Coll Surg. 1995; 180(6):745-53.

12. Rasmussen IB, Berggren U, Arvidsson D, Ljungdahl M, Haglund U. Effects of pneumoperitoneum on splanchnic hemodynamics: an experimental study in pigs. Eur J Surg. 1995;161(11):819-26.

13. Simon RJ, Friedlander MH, Ivatury RR, DiRaimo R, Machiedo GW. Hemorrhage lowers the threshold for intra-abdominal hypertension-induced pulmonary dysfunction. J Trauma. 1997;42(3):398-403.

14. Sugrue M, Jones F, Deane SA, Bishop G, Bauman A, Hillman $\mathrm{K}$, et al. Intra-abdominal hypertension is an independent cause of postoperative renal impairment. Arch Surg. 1999;134(10):1082-5.

15. Mlng M. Intra-abdominal pressure in the intensive care unit: clinical tool or toy? Yearbook of Intensive Care and Emergency Medicine. 2001;2001:2001.

16. Mlng M. Abdominal perfusion pressure as a prognostic marker in intra-abdominal hypertension. Yearbook of Intensive Care and Emergency Medicine. 2002;2002(2002):792-814.

17. Al-Abassi AA, Al Saadi AS, Ahmed F. Is intra-bladder pressure measurement a reliable indicator for raised intra-abdominal pressure? A prospective comparative study BMC Anesthesiol. 2018;18(1):69.

18. Obesity OWH. preventing and managing the global epidemic Report of a WHO Consultation. WHO Technical Report Series. 2000;894:252.

19. Deitel M. The international obesity task force and "globesity." Obes Surg. 2002;12(5):613-4.

20. Morris JA Jr, Eddy VA, Blinman TA, Rutherford EJ, Sharp $\mathrm{KW}$. The staged celiotomy for trauma Issues in unpacking and reconstruction. Ann Surg. 1993;217(5):576-84.

21. Raeburn CD, Moore EE, Biffl WL, Johnson JL, Meldrum DR, Offner PJ, et al. The abdominal compartment syndrome is a morbid complication of postinjury damage control surgery. Am J Surg. 2001;182(6):542-6.

22. Hong JJ, Cohn SM, Perez JM, Dolich MO, Brown M, McKenney MG, et al. Prospective study of the incidence and outcome of intra-abdominal hypertension and the abdominal compartment syndrome. Brit J Surg. 2002;89(5):591-6.

23. Malbrain MLNG, De Iaet I, Van Regenmortel N, Schoonheydt $\mathrm{K}$, Dits $\mathrm{H}$, et al. Can the abdominal perimeter be used as an accurate estimation of intra-abdominal pressure? Crit Care Med. 2009;37(1):316-9.

24. Sugrue M, Bauman A, Jones F, Bishop G, Flabouris A, Parr M, et al. Clinical examination is an inaccurate predictor of intraabdominal pressure. World J Surg. 2002;26(12):1428-31.

25. Malbrain ML. Different techniques to measure intra-abdominal pressure (IAP): time for a critical re-appraisal. Intensive Care Med. 2004;30(3):357-71.

26. Wise RD, Rodseth RN, Correa-Martin L, Sanchez Margallo F, Becker P, Castellanos G, et al. Correlation between different methods of intraabdominal pressure monitoring in varying intraabdominal hypertension models. S Afr J Crit Care. 2017;33(1):15-8.

27. Collee GG, Lomax DM, Ferguson C, Hanson GC. Bedside measurement of intra-abdominal pressure (IAP) via an indwelling 
naso-gastric tube: clinical validation of the technique. Intensive Care Med. 1993;19(8):478-80.

28. Yol S, Kartal A, Tavli S, Tatkan Y. Is urinary bladder pressure a sensitive indicator of intra-abdominal pressure? Endoscopy. 1998;30(9):778-80.

29. Fusco MA, Martin RS, Chang MC. Estimation of intra-abdominal pressure by bladder pressure measurement: validity and methodology. J Trauma. 2001;50(2):297-302.

30. Sugerman H, Windsor A, Bessos M, Wolfe L. Intra-abdominal pressure, sagittal abdominal diameter and obesity comorbidity. $\mathrm{J}$ Intern Med. 1997;241(1):71-9.

31. Lambert DM, Marceau S, Forse RA. Intra-abdominal pressure in the morbidly obese. Obes Surg. 2005;15(9):1225-32.

32. Smit M, Werner MJM, Lansink-Hartgring AO, et al. How central obesity influences intra-abdominal pressure: a prospective, observational study in cardiothoracic surgical patients. Ann Intensive Care. 2016;6:99. https://doi.org/10.1186/s13613-016-0195-8.

33. Ho HS, Saunders CJ, Gunther RA, Wolfe BM. Effector of hemodynamics during laparoscopy: $\mathrm{CO} 2$ absorption or intra-abdominal pressure? J Surg Res. 1995;59(4):497-503.
34. Horvath KD, Whelan RL, Lier B, Viscomi S, Barry L, Buck K, et al. The effects of elevated intraabdominal pressure, hypercarbia, and positioning on the hemodynamic responses to laparoscopic colectomy in pigs. Surg Endosc. 1998;12(2):107-14.

35. Koivusalo AM, Lindgren L. Effects of carbon dioxide pneumoperitoneum for laparoscopic cholecystectomy. Acta Anaesthesiol Scand. 2000;44(7):834-41.

36. Lindberg F, Bergqvist D, Björck M, Rasmussen I. Renal hemodynamics during carbon dioxide pneumoperitoneum: an experimental study in pigs. Surg Endosc. 2003;17(3):480-4.

Publisher's Note Springer Nature remains neutral with regard to jurisdictional claims in published maps and institutional affiliations. 